\title{
LICITAÇÃO NA ADMINISTRAÇÃO PÚBLICA: CUSTOS DA BUROCRACIA PARA SOCIEDADE
}

\section{ARTIGO DE REVISÃO}

OLIVEIRA, Leonardo da Silva de ${ }^{1}$

OLIVEIRA, Leonardo da Silva de. Licitação na Administração Pública: Custos da burocracia para sociedade. Revista Científica Multidisciplinar Núcleo do Conhecimento. Ano 05, Ed. 03, Vol. 10, pp. 90-108. Março de 2020. ISSN: 2448-0959, Link de acesso: https://www.nucleodoconhecimento.com.br/administracao/licitacaona-administracao-publica

\section{RESUMO}

O estudo apresenta a estrutura das licitações e do Direito Administrativo através de parâmetros estabelecidos pelo atual regime, regido pelo modelo burocrático, que sustentou as licitações e contratos na Administração Pública. Não se buscou quantificar a eficiência da aplicação da lei. A tentativa pontual de desburocratização de uma legislação de contratação, criada para casos excepcionais, transforma-se cada vez mais em regra e tendência para contratações futuras na administração do setor público, buscou-se apontar pontos favoráveis e contrários em suas práticas. $\mathrm{O}$ estudo foi desenvolvido através da revisão da literatura.

Palavras-chave: Administração Pública. Licitações, burocracia, desburocratização.

\section{INTRODUÇÃO}

O Direito Administrativo vem constantemente evoluindo frente às necessidades sociais e o processo de expansão e aprimoramento de seus princípios, que permitem

\footnotetext{
${ }^{1}$ Graduando em Administração Pública.
} 
à Gestão e ao Poder Judiciário equilibrar direitos dos administrados frente às prerrogativas do Estado.

O estudo busca analisar o processo licitatório frente à legislação pátria, destacando os custos da Burocracia para a Sociedade e, em contrapartida, observa também a tentativa de desburocratização e seus efeitos práticos.

Os padrões de contratação do Estado por licitação, embora conhecidos, fazem notar que o governo, em todos os níveis, muitas vezes tem dificuldades na aplicação da análise do direito administrativo; talvez em menos tempo, talvez com menos burocracia e mais orçamento seja executada a meta da administração no setor público, que deve contemplar sempre a busca por processos mais claros e eficientes.

No âmbito dos contratos públicos (incluindo concessões e parcerias público-privadas), na busca de melhorar a gestão administrativa, deve-se exortar as autoridades competentes para discutir a busca de melhorias no processo de contratação pública, a partir da perspectiva da administração pública, tendo como pilar fundamental a implementação de sistemas de gestão na aquisição de bens, serviços, obras, e para as modalidades de concessão e associações públicas e privadas.

Não é um problema de norma, vai além, é um problema de pessoas, um problema de gestão, sendo preciso a aplicação da legislação de gestão administrativa, trata-se de buscar compras eficientes, circunscritas a uma ordem constitucional e social, para satisfazer interesses públicos.

Este estudo caracteriza-se inicialmente pelo levantamento bibliográfico e a partir deste, baseamos nossa discussão e debate; sustentados na análise dos fatos comparados ao referencial teórico levantado.

\section{PROCESSO LICITATÓRIO}

Os processos licitatórios buscam obter aquisições e contratos em condições satisfatórias para o ente público, reduzindo o gasto desse setor. 
O inciso XXI, art. 37 da Constituição, impôs à administração pública direta e indireta a necessidade da realização de processo de licitatório para as aquisições, alienações e contratações necessárias as suas atividades (MEIRELLES, 1996); isso como forma de tirar da discricionariedade do administrador público na prerrogativa de escolha dos terceiros a serem contratados.

A Lei $n . \stackrel{0}{8.666 / 93}$ em seu art. $3^{\circ}$ apresenta princípios básicos que regem 0 procedimento licitatório em qualquer modalidade, são eles:

- Igualdade;

- Impessoalidade;

- Publicidade;

- Moralidade;

- Probidade administrativa;

- Vinculação ao edital;

- Julgamento objetivo; e,

- Legalidade.

Di Pietro (2016) esclarece que atos celebrados entre a Administração Pública e pessoas físicas e jurídicas, quer sejam públicas ou privadas, são estabelecidos pelo chamado regime jurídico de direito público e submissos a tais princípios, assim sendo, a contratação relaciona-se ao Estado pela legislação da nação.

Deve-se ressaltar que o processo não atesta a redução, eliminação ou exclusão da relevância de tarefas de atribuição estatal, sendo que não seria a negação da necessidade de realização de certas tarefas, atendimento a determinadas carências ou prestação de serviços específicos. Constatou-se a impossibilidade de o Estado atender a todos esses encargos, individualmente, de modo eficiente e satisfatório. 
A base do problema não se encontra nos fins a que se prestam, mas no processo acolhido para sua realização.

Dessa forma as atividades são "públicas", mas devem ser desenvolvidas fora do âmbito formal do aparato estatal, levando ao surgimento de instituições privadas, segundo seus padrões de eficiência, cuja atividade é complementar a atuação do Estado, na qual a atividade pública extrapola o conceito de Estado, na medida em que outras instituições assumem atuação paralela e complementar àquela desenvolvida pelo Estado, onde a forma jurídica dos processos relaciona-se aos instrumentos presentes na formação do contrato administrativo.

\subsection{LICITAÇÃO PÚBLICA}

A Administração Pública não pode contratar livremente compras, serviços, construir obras, ou alienar bens como funciona nas empresas privadas, é vedado as autoridades competentes, da Administração Pública, celebrarem contratos com particulares para prestarem serviços ao ente público, pois a licitação visa a atender o princípio constitucional da isonomia, desse modo, todas as pessoas interessadas em prestarem seus serviços à Administração poderão oferecê-lo por meio da Licitação.

Gasperini (2005, p. 47) define licitação pública como um "[...] processo administrativo obrigatório que visa a obter a proposta mais vantajosa para execução de contrato ou ato de interesse público [...]"; Di Pietro trata licitações como um grupo de formalidades para práticas de atos administrativos determinados.

Para Meirelles (2012) pode-se definir por procedimento administrativo, aquele em que a Administração Pública escolhe a mais vantajosa proposta para contratação; Dallari (2000) apresenta a licitação como um procedimento administrativo dotado de unilateralidade e discricionariedade cuja finalidade é a contratação visando alienação, prestação de serviços, aquisição de bens e execução de obras. Logo, denota-se que no âmbito da administração pública todos os entes e órgãos são obrigados a licitar. 
As licitações desenvolvem-se seguindo o preceituado na Lei $n . \stackrel{0}{8.666}$ de 1993 que estabelece o conjunto de normas e ritos para licitações e contratos para compras, obras, alienações, serviços e locações. Tais ritos abrangem toda a Administração Pública, seja ela direta ou indireta, inclusive empresas públicas de economia mista e empresas controladas por entes públicos.

Medauar (2007) bem define licitação como uma sucessão de atos e fases que seleciona o proponente que irá contratar com a Administração Pública.

Com base nas definições dos autores, afirma-se que o contrato somente será celebrado com o licitante particular que oferecer proposta vantajosa e reunir condições de cumprir as obrigações expostas no contrato, em nenhum momento as autoridades competentes do procedimento poderão ter preferência por algum particular no processo, pois a principal finalidade da licitação é selecionar a melhor proposta de forma menos dispendiosa aos cofres públicos, assegurando igualdade de condições a todos os participantes.

A necessidade de licitar na Administração Pública decorre dos princípios constitucionais como legalidade, moralidade, impessoalidade, eficiência, publicidade e probidade administrativa, todas tem devem se manifestar necessariamente sempre que se envolver erário público.

Ainda sobre princípios, a eficiência foi incorporada como um princípio pela Emenda Constitucional n. .019 , promulgada em 4 de julho de 1998, cuja proposta era mexer nas bases da Administração Pública, após a Constituição Federal de 1988, a Emenda n.ำ 19 foi a primeira a promover uma grande reforma administrativa no Estado brasileiro e foi a primeira tentativa de romper com o modelo administrativo burocrata de 1930 adotado pela Constituição em 1988.

A Emenda n.. 19 alterou o art. 22 em seu inciso XXVII da Constituição Federal de 1988 e tornou privativo da união, o poder de legislar no que tange a normas gerais de licitações e contratos, em todas as modalidades e em quaisquer poderes ou entes, incluindo a administração indireta. Para empresas públicas e sociedades de economia 
mista, a Emenda trouxe alteração no art. 173, $\S 1^{\circ}$, inciso I, versando que será estabelecido em lei o estatuto jurídico das empresas públicas e das sociedades de economia mista juntamente com suas subsidiárias exploradoras de atividades econômicas. Dentre as atividades econômicas mencionadas estão a comercialização ou produção de bens, ou ainda, prestadoras de serviços, ficando a cargo dessa lei, dispor sobre contratações e licitações para aquisições, obras, alienações e prestações de serviço. Essa foi uma inovação que dava a possibilidade das empresas públicas se livrarem de algumas amarras burocráticas, tornando-se mais competitivas na exploração de suas atividades.

Dallari (2000) fala sobre licitação enquanto processo e descreve algumas de suas fases, e acompanhando o determinado pelo legislador na Lei de Licitações, o autor descreve que todo esse processo busca adotar medidas que regulamentem 0 processamento das requisições; podemos perceber a ideia de processo e regulamentação no art. 38 que versa que a abertura do processo licitatório tem que, necessariamente, estar autuada, protocolada e numerada; e deve conter autorização, descrição do objeto e indicação da fonte de recursos.

Sobre a competência de legislar sobre licitações e contratos Ferraz (1999, p. 19) reforça o previsto no inciso XXVII, art. 22 da Constituição Federal de 1988 que imputa à União, a normatização que divide com o poder Legislativo parte dessa competência.

Cumpridas as formalidades basilares referentes à abertura do processo, cabe a Administração estimar o valor da contratação da compra, obra ou serviço de acordo com o art. 22 da Lei n. ${ }^{\circ}$ 8.666/93 e na sequência optar pela modalidade que se encaixe ao objeto da contratação.

A Lei n. 8.666/93 possibilita optar por cinco modalidades, que são a concorrência, convite, tomada de preços, leilão e concurso cada qual com seu conjunto de especificidades e peculiaridades; veremos na sequência algumas modalidades acompanhadas de suas características e distinções. 
As peculiaridades e diferenças já começam a surgir quando da criação do instrumento convocatório com exigências específicas para as modalidades de concorrência e tomada de preços por força do prescrito no art. 40 da LLC.

As modalidades de licitação seguem ritos distintos, o que provoca dificuldades na compreensão e direcionamento dos pleitos de forma adequada, de acordo com o disposto na lei.

As diferentes liturgias delineadas para cada uma das modalidades objetivam dar celeridade à tramitação processual e minimizar os custos gerados para contratação pela Administração.

Pode-se observar dispositivos de tratamento diferenciado às modalidades de licitação no $\S 4^{\circ}$ do art. 43 , cujos procedimentos do caput somente se aplicam à concorrência e, no que couber, ao concurso, leilão, tomada de preço e convite. O mesmo fato também poderia ser apreciado no Decreto-Lei n.․ 2.300/86, já revogado, que no caput de seu art. 33 versava que a concorrência seria processada e julgada com procedimentos nele fixados, note-se que o legislador se direciona à modalidade específica e não à licitação de modo geral. Vemos esse mesmo padrão no art. 22 que qualifica e individualiza a cada uma das modalidades segundo o fim a que se presta.

Dentre as modalidades de licitação a concorrência é a que permite preliminarmente a qualificação dos participantes de forma detalhada e isso ainda em etapa anterior a de habilitação, com previsão no art. $22, \S^{1} 1^{\circ}$ e art.43, inciso I.

Posteriormente, tendo sido verificadas as condições inscritas no art. 27, a saber: habilitação jurídica, qualificação técnica e econômico-financeira, e por último a regularidade fiscal e trabalhista; são analisadas as condições de execução do serviço a ser contratado e é emitido parecer deferindo ou não, seguindo a fase de interposição de recurso conforme alínea a, inciso I, art.109.

Findo a fase recursal, temos uma lista de participantes aptos à disputa que definirá o vencedor a partir da análise das propostas por estes oferecidas (DI PIETRO, 1995). 
Ferraz (2009) esclarece que a concorrência destina-se a grandes contratações que envolvem grande dispêndio de recursos e deve ser precedida sempre de ampla divulgação e publicidade.

A modalidade de tomada de preços de acordo com o art. 22, §2 concorrência, não prevê fase preliminar à habilitação, podendo participar interessados devidamente cadastrados; o cadastro é o momento em que se levantam as condições do participante e este procedimento em sua maioria precede à abertura do próprio certame conforme descreve Di Pietro (1995), reforçado por Ferraz (2009), que descreve a tomada de preço como uma modalidade para contratações de médio vulto, cabendo a participação de qualquer interessado cadastrado.

Tratando-se ainda da tomada de preços, após iniciado o certame, os interessados cadastrados e julgados aptos requerem sua inserção no pleito, e aos não cadastrados também é permitida a participação, claro, mediante o devido cadastro que deverá ocorrer até três dias que antecedem ao recebimento dos envelopes contendo as propostas; vale ressaltar que a verificação referente à fase de habilitação com a análise documental é realizada no cadastramento, logo, não se repetirá.

Conhecido como convite, este constitui uma modalidade bem mais simples de licitação. Para Ferraz (2009), o convite destina-se a contratos de pequeno vulto, onde cabe a participação de cadastrados e não cadastrados que poderão ser escolhidos e convidados à participação. $O$ interessante dessa modalidade está na qualificação dos convidados que pode ser presumida além da habilitação preliminar que também pode ser realizada; vale ressaltar que interessados não convidados também podem requerer participação na disputa.

A partir da visão analítica das modalidades de licitação, destaca-se o fato de que, para cada uma delas existe uma cesta de regras e procedimentos distintos e peculiares, das quais o gestor público não pode abster-se sob pena de prejuízo ao princípio da legalidade, norteador dos procedimentos licitatórios e das ações da Administração de modo geral, mas embora ambas as modalidades tenha fins comuns, a contratação, 
por caminhos e regras distintos, também temos semelhanças a exemplo da fase de verificação da habilitação documental com deferimento ou não, que pode até ocorrer em momentos diferentes nas modalidades, mas é comum a todas elas.

\subsection{ARTS. 70 E 71 DA LEI DE LICITAÇÕES}

No século $X X$ os serviços públicos, eram em regra, prestados diretamente pelo Estado, porém este não conseguia responder de forma eficaz aos anseios dos administrados.

A insatisfação da Coletividade impulsionou o fortalecimento da delegação dos serviços Públicos. Assim, a prestação de serviço público por particulares adquire nova feição no contexto jurídico brasileiro.

No entanto ressalta-se que a Constituição Federal de 1988 foi silente no que tange a forma indireta de contratação de trabalhadores, a terceirização.

Somente através do Decreto-Lei n. 200/1967 nasceu a possibilidade de que a Administração Pública no âmbito Federal recorresse a execução indireta, mediante contrato.

Segundo a Lei de Licitações arts. 70 e 71, a responsabilidade pelos danos causados a terceiros e à Administração, decorrentes de sua culpa ou dolo ao executar o objeto contratual, é do contratado, o que não exclui ou reduz a responsabilidade do órgão estatal interessado.

A responsabilidade consagrada no referido artigo é do tipo subjetiva, depende de demonstração de dolo ou culpa do contratado no exercício do objeto do contrato. Portanto, caso o contratado cause algum dano a particulares no decorrer da execução do contrato, deverá responder diretamente pelo prejuízo causado. 


\subsection{MODERNIZAÇÃO DAS LICITAÇÕES}

A Medida Provisória ก.. 495/2010, posteriormente convertida na Lei n. .9 12.349/10 acrescentou alterações expressivas na Lei de Licitações com o objetivo de implementar mecanismos de proteção aos produtos e serviços nacionais.

Cabe ressaltar que naquele período, o Brasil passava por uma fase de grande crescimento econômico na contramão das principais economias mundiais, fato esse, que valorizou nossa moeda frente ao dólar, por esse motivo, a tendência natural era ter um aumento avassalador nas importações, o que prejudicou sistematicamente a indústria nacional e forçou o governo a medidas intervencionistas que é o que se desenha na Lei n.. $12.349 / 10$.

A ideia de direcionar preferência, de modo legal, nos processos licitatórios já era defendida por Motta (2000, p. 127) e nesse sentido, a Lei n. 0 12.349/10 trouxe a alteração do art. $3^{\circ}$ da LLC nos parágrafos 5, 6, 7, 8, instituindo um modelo de margem de preferência dando preferência aos produtos nacionais nas licitações, principalmente os manufaturados e serviços nacionais resultantes de inovações tecnológicas desenvolvidas no Brasil.

A margem de preferência fixada pelo §8 ficou limitada a $25 \%$ incididos sobre o preço dos produtos estrangeiros, vale ressaltar que a lei também estendeu tais benesses aos países que compõe o bloco do Mercosul.

Ainda no ano de 2010, o Supremo Tribunal Federal pôs fim a um entrave jurídico ligado a LLC ao declarar constitucional o $\$ 1$ do art. 71, que versa que os débitos trabalhistas, comerciais e fiscais não podem ser transferidos à Administração, onerar o contrato e nem restringir a regularização e a utilização de edificações e obras, inclusive no registro de imóveis.

O que gerou o conflito foi um entendimento oposto exarado pelo Tribunal Superior do

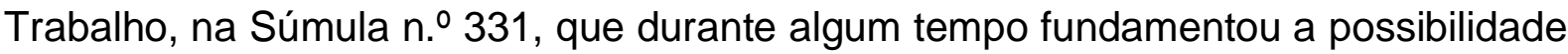


de transferência de débitos trabalhistas à Administração, que foi devidamente corrigido pelo STF.

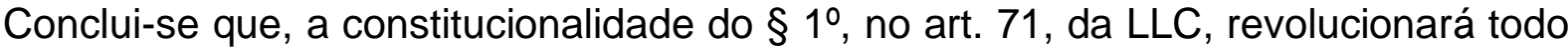
o ordenamento jurídico, haja vista que os Advogados deverão provar as falhas da Administração, seja na contratação, quando não lance mão de cauções como prevê o art. 56 da Lei de Licitação, seja na contratação de empresa inidônea, seja na falta de fiscalização.

Quanto ao Magistrado caberá uma análise pormenorizada do caso, julgando cada caso segundo suas particularidades.

Quanto aos entes públicos caberá colher os frutos de uma boa ou má administração, sendo avaliada por suas contratações de acordo com suas ações. Enfim freando as decisões de massa, da forma que eram feitas.

Quanto aos trabalhadores, também administrados, deverão ser pessoas atuantes para exigirem cotidianamente o cumprimento de seus direitos, tanto da Empresa Contratada, enquanto empregados, quanto do Ente Público, enquanto administrados, não deixando acumular todos os seus direitos tendo em vista a incerteza de receber como outrora estava sendo feito.

A constitucionalidade do $\S 1^{\circ}$, no art. 71 , da LLC, em nada afastou a possibilidade da Administração Pública responder subsidiariamente pelos danos causados aos trabalhadores quando provada sua culpa diante da omissão em sua função fiscalizatória da execução contratual ou na escolha da empresa contratada, porém afastou por inteiro a responsabilidade objetiva tal como vinha sendo aplicado pela justiça do trabalho.

\subsection{CUSTOS DA BUROCRACIA}

A Constituição Federal de um país representa o conjunto de leis fundamentais, a fim de organizar e conduzir o seu bom funcionamento, sendo acatada como a lei máxima 
e obrigatória para todos os cidadãos da nação e garantindo os seus direitos e deveres. De modo geral, por sua vez, o regime jurídico brasileiro é marcado por excessos de burocracia que representam um entrave para a sociedade, trazendo consequências sociais e econômicas.

A burocracia atualmente é um tema que desperta distintos conceitos e percepções; para o senso comum, refere-se a longos processos, excesso de formalismo, morosidade nas soluções, já para os burocratas clássicos, é ligada à racionalidade e a eficiência de processos.

$\mathrm{Na}$ verdade, o principal conceito de burocracia foi forjado a partir dos estudos de Weber. Partindo de um conceito histórico em que Max Weber observou a transição da idade média para a idade moderna e as mudanças ocorridas principalmente nas relações sociais que migraram de uma base tradicional e carismática para uma base instrumental e legalista.

Para Weber (1982) a burocracia é uma forma de organização social essencialmente capitalista, baseada na racionalização, cuja estrutura estabelece uma hierarquia formal, rígida e impessoal.

As grandes corporações privadas atualmente se utilizam de princípios burocráticos, mas que tendem a se manifestar de forma bastante eficiente devido às exigências de um mercado competitivo e dinâmico.

Para Moe (1987, p. 290) o conjunto característico da Administração Pública, fatalmente, pratica o modelo burocrático sem a eficiência alcançada no setor privado, o autor conclui, afirmando haver uma "ineficiência congênita" no setor público, fruto da competição política e apropriação da burocracia estatal.

Weber considera o Estado uma associação de burocracia civil e militar; daí sua perspectiva de que o Estado detém o monopólio da violência desenvolvido a partir de dois direitos ou poderes básicos como o poder de legislar, de forma que os cidadãos 
não possam escapar; e o poder de recolher impostos dos quais os cidadãos também não podem igualmente escapar.

Prestes Mota (1981) afirma que burocracia é poder e, tal como o antagonismo presente no capitalismo entre a burguesia, detentora dos meios de produção, e o resto da população, que não detém, é também observado na burocracia, uma vez que alguns grupos ou classes exercerão o poder burocrático estatal (dominantes) em detrimento de outros (dominados).

Moe (2006) afirma que as burocracias são instituições impostas por vencedores aos perdedores; tomando por base os argumentos de Weber e Prestes Mota, pode-se afirmar que o Estado é uma organização burocrática que detém o poder e dominação, constituída de forma elitista com funcionalismo civil e militar, dotado do poder de legislar e tributar, ou seja, o "Poder".

A sociedade organizacional é por si só uma sociedade burocrática por conveniência, nascida da produção de um Estado, é uma sociedade consumista, que expande-se para todos os aspectos da vida social. A burocracia contemporânea, em excesso, no nível de formações sociais concretas, implica em uma política econômica e uma economia política, muita das vezes retrógrada e ineficiente, como no caso das licitações.

\subsection{RDC: A EXPERIÊNCIA BRASILEIRA DE DESBUROCRATIZAÇÃO}

A Lei n.. 12.462/11 que converteu a Medida Provisória n.ำ 527, de 2011, trata-se do Regime Diferenciado de Contratações editado para um contexto pontual e específico, pois o Brasil se encontrava às vésperas de receber dois grandes eventos internacionais que eram a Copa do Mundo FIFA de 2014, e logo a seguir, os Jogos Olímpicos Rio 2016; ambos os eventos demandariam volume grande de contratações de obras para construção de estádios, arenas, hospedagens aos atletas e outras de infraestrutura (portos, aeroportos e outros). 
Até então o único meio de contratação válido no Brasil era a Lei $n$. ․ 8.666/93, com algumas inovações como, por exemplo, o pregão e o pregão eletrônico, baixadas pela

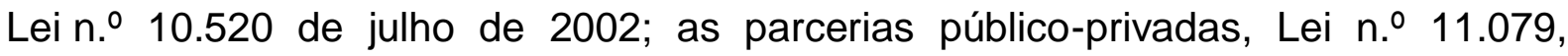
publicada em dezembro de 2004; e outros pequenos ajustes. Considerando as características do modelo licitatório nacional julgado como um processo burocrático, lento e moroso diante da necessidade de contratações para os eventos, nasceu o Regime Diferenciado de Contratação, inicialmente por uma medida provisória baixada pelo executivo. Daí já se desenvolveu o primeiro aspecto crítico ligado ao novo Regime: "pode o executivo legislar sobre a forma contratação e criar formas de controle para si próprio? Legislar, controlar não é função legislativa?"; pode até ser justificável considerando o já citado inciso XXVII, art. 22 da Constituição Federal de 1988.

A proposta do principal do RDC era trazer inovações que tornassem o processo de contratação mais flexível e veloz subsidiariamente à Lei de Licitações. Algumas inovações tiveram por fonte experiências positivas de dispositivos, já instituídos, como pregão eletrônico e outros, associados a procedimentos positivados em outros países.

Como principais alterações, da nova modalidade de licitação, podemos citar inversão de fases (análise da documentação apenas do vencedor), possibilidade de divulgação dos valores esperados para o gasto apenas aos órgãos de controle de forma que a

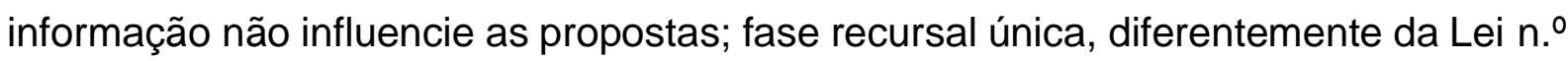
8.666/93 o RDC não admite recurso a cada fase do processo, mas sim no final; outra inovação foi a ideia de anteprojeto, no modelo da Lei de Licitações seria necessário que o órgão licitante apresentasse um projeto básico, o RDC permite que os participantes apresentem anteprojeto com formas de execução e tecnologias a serem empregadas a sua escolha.

Não é possível negar que o RDC trouxe avanços à forma de contratação pública no Brasil, mas até hoje essa flexibilização ou desburocratização é questionada por conta de brechas que se abrem para distorções que deixaram o país suscetível aos escândalos de corrupção que posteriormente vieram à tona. Um dos principais pontos 
críticos ligados ao RDC foi a sua expansão, a lei que fora criada tão somente para atender à Copa e as Olimpíadas, em regime de exceção, fora rapidamente expandida para outros pontos de interesse estatal, tornando-se regra, a exemplo do PAC, áreas de Saúde e Educação pelas Leis n.ำ12.688/2012, n.ำ12.722/2012 e n.ำ12.745/2012.

Outro aspecto crítico é que a flexibilização, proposta pela lei, não veio acompanhada, na mesma medida, de instrumentos de controle e responsabilização que punissem tanto o contratado, quanto o gestor, responsável pelo certame, que dentro do novo modelo tem maior liberdade discricionária e menor responsabilização; outro questionamento é que o RDC promove o desprezo à supremacia do interesse público ao colocar os participantes e o contratante (governo) em igualdade de condições numa relação que anteriormente sempre teve o contratante em nível superior pela representação do interesse público.

Podemos concluir que, o RDC foi uma junção de dispositivos já vigentes em campos específicos do arcabouço jurídico das contratações públicas aliados a outros dispositivos importados de países neoliberais, na época da Copa e das Olimpíadas, para desburocratizar e modernizar da Lei das Licitações, mas que na verdade abriu brechas a muitos dos esquemas de corrupção hoje investigados; atestando que a ideia de desburocratização desacompanhada da devida responsabilização e controle não são os melhores caminhos para o desenvolvimento econômico e social.

\section{CONCLUSÃO}

No Brasil ainda não há como ter uma superação da burocracia em virtude de toda uma raiz histórica e cultural herdada de nossos colonizadores e perpetuada. Em determinados aspectos, o modelo burocrático se mostrou eficiente enquanto estrutura que permitiu administrar uma grande quantidade de indivíduos e, no setor privado, mesmo após tantos anos de sua idealização e propagação, ainda é um modelo funcional.

No setor público, após análise, do nosso modelo licitatório, percebe-se que se mantém atuais as observações descritas por Moe (1987) afirmando a existência de uma

Disponível em: https://www.nucleodoconhecimento.com.br/administracao/licitacao-naadministracao-publica 
"ineficiência congênita", mas que a primeira vista não parece pertencer ao modelo burocrático, mas ligado às práticas do sistema político aliado a um excesso de burocracia já característico do regime jurídico brasileiro.

Debruçando-se sob a análise da experiência brasileira de desburocratização que se desdobrou para um quadro caótico de corrupção, nota-se o quanto são nocivos ambos os polos que envolvem o excesso de burocracia e o excesso de desburocratização. Neste trade-off se percebe que está em voga muito mais que as estruturas e os procedimentos, que poderiam facilitar a Administração de modo geral, mas as ideias demostradas por Prestes Motta (1987) do exercício de poder e dominação.

A Lei de Licitações embora tenha evoluído desde a sua promulgação em 1993, fornecendo aos gestores mais ferramentas e possibilidades, ainda não é suficientemente moderna para maximizar a eficiência nas contratações estatais, a ideia de em menos tempo, com menos burocracia se executar mais orçamento ainda não é realidade. Neste momento tramita no Congresso Nacional o projeto de Lei n.. 6.814/17 que está sendo debatido e que talvez satisfaça a necessidade de adequações carentes no modelo atual.

Para finalizar, cabe reforçar que este estudo não esgota a temática discutida. De forma contrária, busca incentivar e conscientizar sobre a necessidade de mais estudos e maior aprofundamento do tema discutido.

\section{REFERÊNCIAS}

BRASIL. Constituição (1988). Emenda constitucional n. 19, de 4 de junho de 1998. Disponível em: <http://www.planalto.gov.br> Acesso janeiro de 2020.

BRASIL. Constituição da República Federativa do Brasil. Brasília, DF: Senado Federal, 1988. Disponível em: <http://www.planalto.gov.br> Acesso janeiro de 2020.

BRASIL. Decreto-lei n. 2.300, de 21 de novembro de 1986. Disponível em: $<$ http://www.planalto.gov.br> Acesso janeiro de 2020. 
BRASIL. Decreto-lei n. 200, de 25 de fevereiro de 1967. Disponível em: $<$ http://www.planalto.gov.br> Acesso janeiro de 2020.

BRASIL. Lei № 12.462, de 4 de Agosto de 2011. Disponível em: <http://www.planalto.gov.br> Acesso março de 2020.

BRASIL. Lei № 8.666, de 21 de junho de 1993. Disponível em: <http://www.planalto.gov.br> Acesso março de 2020.

BRASIL. Lei № 12.349, de 15 de dezembro de 2010. Disponível em: $<$ <ttp://www.planalto.gov.br> Acesso março de 2020.

BRASIL. Lei № 10.520, de 17 de julho DE 2002. Disponível em: $<$ http://www.planalto.gov.br> Acesso março de 2020.

BRASIL. Lei № 12.688, de 18 de julho de 2012. Disponível em: <http://www.planalto.gov.br> Acesso março de 2020.

BRASIL. Lei № 12.745, de 19 de dezembro de 2012. Disponível em: <http://www.planalto.gov.br> Acesso março de 2020.

BRASIL. Lei № 12.722, de 3 de outubro de 2012. Disponível em: $<$ <ttp://www.planalto.gov.br> Acesso março de 2020.

BRASIL. Lei № 11.079, de 30 de dezembro de 2004.. Disponível em: <http://www.planalto.gov.br> Acesso março de 2020.

BRASIL. Entenda como funciona o RDC. Disponível em: <http://www.pac.gov.br/noticia/564012c0>. Acesso em: 04 de agosto de 2018.

Brasil. Tribunal de Contas da União. Licitações e contratos: orientações e jurisprudência do TCU / Tribunal de Contas da União. - 4. ed. rev., atual. e ampl. Brasília : TCU, Secretaria-Geral da Presidência : Senado Federal, Secretaria Especial de Editoração e Publicações, 2010. 
CELESTINO, Fernanda. Regime Diferenciado de Contratações: breves comentários à exceção que virou tendência. Fortaleza: Tribunal de Contas do Ceará, 2015.

COELHO MOTA, Carlos Pinto. Eficácia nas licitações e Contratos - Estudos e comentários sobre as leis $8.666 / 93$ e $8.987 / 95$, com a redação dada pela lei 9.648/98. Belo Horizonte: Del Rey, 1999.

DALLARI, Adilson Abreu. Aspectos Jurídicos da Licitação. 5 edição. São Paulo: Saraiva, 2000

DI PIETRO, Maria Sylvia Zanella, RAMOS, Dora Maria de Oliveira.SANTOS, Márcia Valquiria dos \& D'AVILA, Vera Lúcia Machado. Licitações e contratos. 2. ed. São Paulo, Malheiros Ed., 1995

DI PIETRO, Maria Silvia Zanella. Direito Administrativo. São Paulo: Atlas, 2000

DI PIETRO, Maria Sylvia Zanella. Direito administrativo. 27. ed. São Paulo: Atlas, 2014.

DI PIETRO, Maria Sylvia Zanella. Direito Administrativo. Forense: 29ㅡㄹ Ed. 2016.

FERNANDES, Jorge Ulisses Jacoby. RDC: 0 Regime Diferenciado de Contratações Públicas: Lei № 12.462, de 5 de agosto de 2011. Belo Horizonte: Fórum, 2012.

FERRAZ, O controle dos atos administrativos e os princípios fundamentais. Malheiros, 1999.

FIGUEIREDO, Lúcia Valle. Direito dos Licitantes. 4 edição. São Paulo: Malheiros, 1994.

GASPERINI, Diógenes. Direito Administrativo. São Paulo: Saraiva, 1993.

GASPERINI, Diógenes. Direito administrativo. 10ªe ed. São Paulo: Saraiva, 2005 
GIAMBIAGI, Fábio e ALÉM, Ana Cláudia. Finanças Públicas, Teoria e Prática. 2 tiragem. Rio de Janeiro: Campus, 1999.

JUSTEN FILHO, Marçal. Comentários à Lei de Licitações e Contratos Administrativos. 14ª ed. - São Paulo: Dialética, 2010.

KOHAMA, Hélio. Contabilidade Pública. 3.ed. São Paulo: Atlas, 1993.

MEDAUAR, Odete, Direito administrativo moderno. $7^{\text {a }}$ ed. São Paulo: Revista dos Tribunais, 2007.

MEIRELLES, Hely Lopes. Direito administrativo brasileiro. 32. ed. São Paulo: Malheiros, 2006.

MEIRELLES, Hely Lopes. Licitação e Contrato Administrativo. 15. ed. São Paulo: Malheiros, 2010.

MEIRELLES, Hely Lopes; ALEIXO, Délcio Balestero; BURLE FILHO, José Emmanuel. Direito administrativo brasileiro. 38. ed. São Paulo: Malheiros, 2012.

MOE, T. 1987. The Positive Theory of Public Bureaucracy. In: D.C. Mueller. Perspective of Public Choice: A Handbook. Cambridge, UK: Cambridge University Press.

MOE, T. 2006. Power and Political Institutions. In: I. Shapiro; S. Skowronek; D. Galvin, eds. Rethinking Political Institutions. New York: New York University Press.

MOREIRA, Egon Bockmann; GUIMARÃES, Fernando Vernalha. Licitação Pública a Lei Geral de Licitação - LGL e o Regime Diferenciado de Contratação - RDC. São Paulo: Malheiros, 2012.

MOTA, Carlos Pinto Coelho. Eficácia nas licitações e contratos. 6 edição. Belo Horizonte: Del Rey, 1997. 
MOTA, Carlos Pinto Coelho. Palestra síntese do processo licitatório. Belo Horizonte: Ed. Del Rey, 2000.

MOTTA, Carlos Pinto Coelho. Responsabilidade Fiscal. Belo Horizonte: Del Rey, 2000.

PEIXOTO, Ariosto Mila. RDC (Regime Diferenciado de Contratações). Disponível em: <http://novo.licitacao.com.br/apoio-juridico/artigos/107-rdcregime-diferenciadode-contratacoes. html>. Acesso janeiro de 2020.

PINHEIRO, Jorge. Aplicabilidade do Uso do Pregão em Litações. Campinas, UNICAMP, 2001.

PRESTES MOTTA, F. C. O que é burocracia. São Paulo: Brasiliense, 1981.

REZENDE, Renato Monteiro. O Regime Diferenciado de Contratações Públicas: comentários à Lei no12.462, de 2011. Disponível em: <http://www. senado.gov.br/senado/conleg/textos_discussao/TD100-RenatoRezende.pdf>. Acesso em Setembro de 2018.

VIEGAS, Cláudia Mara de Almeida Rabelo. A distinção entre normas e princípios. In: Âmbito Jurídico, Rio Grande, XIV, n. 86, mar 2011. Disponível em: $<$ <ttp://www.ambito-

juridico.com.br/site/?n_link=revista_artigos_leitura\&artigo_id=9091>. Acesso janeiro de 2020.

WEBER, M. Ensaios de sociologia. 5.ed. Rio de Janeiro: LTC Editora, 1982.

Enviado: Janeiro, 2020.

Aprovado: Março, 2020. 